\title{
A PRÁTICA DO ACOMPANHAMENTO TERAPÊUTICO COMO ESTRATÉGIA DE EXPANSÃO TERRITORIAL: UMA INCURSÃO CARTOGRÁFICA
}

THE THERAPEUTIC ACCOMPANIMENT APPROACH AS TERRITORIAL EXPANSION STRATEGY: A CARTOGRAPHIC INCURSION

Mariana Ribeiro Marques

Pontifícia Universidade Católica do Rio de Janeiro, Rio de Janeiro/RJ, Brasil

\begin{abstract}
RESUMO
Este artigo se propõe a discutir a prática de Acompanhamento Terapêutico em sua dimensão territorial a partir de um trabalho realizado através de um Centro de Atenção Psicossocial (CAPS). Será analisado o conceito de território adotado pela Reforma Psiquiátrica, suas particularidades e possíveis interlocuções com outras concepções teóricas, como a de Gilles Deleuze e Félix Guattari. A partir da experiência no CAPS, pretende-se cartografar a relação produzida entre os usuários, o serviço e o território da cidade em dispositivos que, através da construção de outras redes de referências, produzam novas relações entre as pessoas e os espaços, tanto urbano, como dos serviços substitutivos ao manicômio. São descritas duas experiências de Acompanhamento Terapêutico em que a interlocução com o território e a construção de uma rede de referências na cidade está atrelada à criação de territórios existenciais para além da lógica asilar, configurando-se como uma estratégia privilegiada para a desinstitucionalização.
\end{abstract}

Palavras-chave: acompanhamento terapêutico; território; cartografia; reforma psiquiátrica; rede.

\begin{abstract}
This article intends to discuss the therapeutical accompaniment practice considering its territorial dimensions within the work done at a Centre for Psycho-social Attention. The territory will be analyzed taking into account the concept used by the Psychiatric Reformation, along with its particularities and possible interactions with other theoretical concepts, such as the one enlighten by Gilles Deleuze and Félix Guattari. We intend to map the encounters produced upon the relations between the users, the services and the city's territory, bringing up devices that can contribute with different references, in a sense that new relations can be enabled. Two experiences are described, to illustrate that the interaction between the territory and the construction of a different network references in the city, is connected with the creation of existential territories beyond the logic applied at mental hospitals, establishing a privileged strategy for un-institutionalization.
\end{abstract}

Keywords: therapeutical accompaniment; territory; cartography; psychiatric reformation; network.

Este artigo apresenta um relato e uma reflexão sobre uma experiência de estágio no CAPS Clarice Lispector, localizado na Zona Norte do Rio de Janeiro. Nessa experiência, o Acompanhamento Terapêutico $(\mathrm{AT})^{1}$ se deu tanto na forma do acompanhamento de usuários na resolução de questões do dia a dia e na formação de vínculos sociais através de andanças pela cidade, como na forma da construção de uma rede de referências na comunidade através de atividades coletivas no território urbano. Neste artigo, será empreendida uma reflexão sobre a noção de território, relacionada à prática na saúde mental e à clínica do $\mathrm{AT}$, assim como serão relatadas duas experiências em que o AT se realizou como uma experiência coletiva de construção de rede e de expansão territorial: a elaboração de um jornal de bairro junto com os usuários do CAPS, que envolveu uma importante articulação com o território, tanto para os usuários como para o CAPS; e a experiência com o bloco carnavalesco "Loucura Suburbana", na produção do show de abertura do II Fórum Internacional de Saúde Coletiva, Saúde mental e Direitos Humanos e no desfile carnavalesco que ocorre anualmente.

O CAPS Clarice Lispector situa-se ao lado do Instituto Municipal de Assistência à Saúde (IMAS) 
Nise da Silveira, que funciona no local onde foi fundado, em 1911, um manicômio originalmente denominado de Colônia de Alienadas do Engenho de Dentro. Muitos usuários do CAPS, que hoje moram em residências terapêuticas ou próprias, tendo com o Centro de Atenção um vínculo diferenciado, foram internos do antigo manicômio, que funcionou por muitos anos no espaço que compreende tanto o IMAS como o CAPS. Hoje CAPS e IMAS funcionam de forma independente, porém, ainda mantêm grande proximidade geográfica. Os usuários do CAPS que moram em residências terapêuticas fazem parte em sua maioria do Programa de Moradias mantido pelo Instituto, o que resulta na constante interlocução entre CAPS e IMAS.

No entanto, a proximidade entre CAPS e IMAS também faz com que o Instituto demande do CAPS iniciativas que algumas vezes ultrapassam as suas atribuições por serem marcadas por uma ideia de cuidado total, própria de um hospital psiquiátrico, e não de um CAPS. Assim, é preciso que o CAPS, através de sua equipe, empreenda um esforço constante em direção ao território. Mas, se a presença do CAPS é fundamental no processo de desinstitucionalização de antigos internos do IMAS, a posição que ocupa na rede também traz o risco de manter a lógica institucional em um serviço que deve estar voltado para o território, e não para o interior do hospital psiquiátrico, o qual deve substituir. No esforço de se voltar para o território, é preciso que o CAPS auxilie na própria construção desse território, o que ultrapassa a ideia de um espaço meramente geográfico, passando a abarcar também uma noção de território existencial. Nesse sentido, o AT é uma ferramenta fundamental, já que essa prática atua justamente na construção de mediações entre territórios diversos.

No contexto da reforma psiquiátrica brasileira, Suely Rolnik (1997) fala do AT como uma nova prática que surge diante da necessidade de se construírem mediações entre territórios como os ambulatórios de saúde mental e hospitais dia, e a família. Além disso, essas mediações seriam realizadas entre esses territórios e a cidade no sentido da necessidade de "criar possibilidades reais de vida não doente" (Rolnik, 1997, p. 84), em que o at pudesse atuar no sentido da potencialização desse processo. Assim, a prática do AT não se dissocia de um trabalho tecido em rede, mesmo que a rede formal de atenção psicossocial ainda não funcione nesse modelo/formato.

Não se trata, então, de esperar que a rede se estruture para começar a utilizá-la. É preciso tecê-la no nível material através do contato com o território e não esperar que o seu funcionamento esteja atrelado a um procedimento formal, como a uma lei. Não adiantaria decretar que os serviços devem ser territoriais se não houvesse o contato efetivo entre os eles e seus usuários e técnicos com a comunidade. Nesse sentido, o AT é uma prática fundamental ao processo de desinstitucionalização preconizado tanto pela Reforma Psiquiátrica como pela Luta Antimanicomial e o território é uma noção imprescindível a essa prática.

\section{O campo do AT: construção de rede e desterritorialização}

$\mathrm{Na}$ esteira da "VIII Conferência Nacional de Saúde" (Ministério da Saúde, 1986), a Constituição Federal de 1988 prevê como diretriz das ações e serviços públicos em saúde, que devem integrar uma rede regionalizada e hierarquizada e constituir um sistema único (SUS), a descentralização, o atendimento integral e a participação da comunidade (art.198). No âmbito específico da saúde mental, a "Declaração de Caracas" (1990, s/p.), da qual o Brasil é signatário, afirma que "as legislações dos países devem ajustar-se de modo que assegurem o respeito aos direitos humanos e civis dos doentes mentais e promovam a organização de serviços comunitários de saúde mental". Como se vê, as determinações legais concernentes à criação de uma rede de saúde - que inclui a saúde mental - regionalizada e descentralizada, que permita a participação da comunidade, são do fim da década de 80 , começo da década de 90 . Porém, a construção material dessa rede é um processo que ainda está em curso, apesar dos grandes avanços que já alcançou.

O caráter comunitário que a rede de assistência em saúde mental deve assumir se opõe a um modelo hospitalocêntrico, em que o hospital psiquiátrico centraliza todos os recursos existentes no âmbito da saúde mental. A reformulação da assistência presente nas diretrizes da Reforma Psiquiátrica brasileira aponta para a estruturação de uma rede que atue na comunidade, garantindo a integralidade da assistência, sua continuidade, e promovendo a reabilitação psicossocial. Dessa forma, o território passa a ser uma noção imprescindível para a construção da rede de assistência em saúde mental e o AT, um instrumento clínico-político indispensável. De acordo com os princípios do SUS e da Reforma Psiquiátrica, a construção de uma rede comunitária de cuidados é fundamental para a consolidação da Reforma Psiquiátrica. A articulação em rede dos variados serviços substitutivos ao hospital psiquiátrico é crucial para a constituição de um conjunto vivo de referências capazes de acolher a pessoa em sofrimento mental. 
Essa rede é maior, no entanto, do que o conjunto dos serviços de saúde mental do município. Uma rede se conforma na medida em que são permanentemente articuladas outras instituições, associações, cooperativas e variados espaços das cidades. A rede de atenção à saúde mental do SUS define-se assim como de base comunitária. É, portanto, fundamento para a construção dessa rede a presença de um movimento permanente, direcionado para os outros espaços da cidade, em busca da inclusão/ emancipação das pessoas com transtornos mentais. De acordo com as diretrizes traçadas na Conferência Regional de Reforma dos serviços de Saúde Mental, realizada em 2005:

\begin{abstract}
A idéia fundamental aqui é que somente uma organização em rede, e não apenas um serviço ou equipamento, é capaz de fazer face à complexidade das demandas de inclusão de pessoas secularmente estigmatizadas, em um país de acentuadas desigualdades sociais. É a articulação em rede de diversos equipamentos da cidade, e não apenas de equipamentos de saúde, que pode garantir resolutividade, promoção da autonomia e da cidadania das pessoas com transtornos mentais. Para a organização desta rede, a noção de território é especialmente orientadora. (Ministério da Saúde, 2005, p.25)
\end{abstract}

A adoção de um modelo de base territorial se conjuga com o objetivo de desinstitucionalização presente no processo de Reforma Psiquiátrica, mas para que esta efetivamente ocorra é necessário que a rede forneça um suporte diversificado que substitua o circuito "emergência-internação-ambulatóriointernação" (Delgado, 1999, p.116), ou, em outras palavras, doença mental-estigmatização-exclusão social-institucionalização. Para isso, é preciso construir uma rede não só de serviços, sejam serviços de saúde mental ou não, mas uma rede de referências sócio-econômico-culturais, que atue de maneira a impedir que o usuário dos serviços de saúde mental seja excluído da convivência em sociedade, a qual por si só já é "desinstitucionalizante". Segundo Delgado (1999, p. 117), a acepção de território da Psiquiatria Democrática italiana, uma das experiências em que a Reforma Psiquiátrica brasileira se inspira, "designa o extra-institucional, marcado por limites geográficos, culturais e sócio-econômicos". Para Rotelli (1992, p. 78), "a presença de transformação no interior das instituições públicas deve ter reflexo em sua capacidade de encontrar recursos que estão fora dela".

Os CAPSs são - ou devem ser - os serviços que ordenam a rede 3 . Dessa forma, pode-se entender que a rede deve se constituir a partir dos CAPSs, que ocuparão assim um lugar central. No entanto, um dos atributos da rede é a sua descentralização, característica imanente à sua natureza. Assim, os CAPSs têm um papel paradoxal, pois devem fazer com que a rede se expanda para além do seu raio de atuação e, ao mesmo tempo, devem atrair para si a demanda de uma determinada área geográfica (Passos, 2004). Como, então, fazer com que o CAPS funcione como propulsor da rede, incitando a sua expansão, se ele deve chamar para si essa rede?

Para responder a questões como essa, Eduardo Passos (2004) chama a atenção para a "experiêncialimite" diante da qual o movimento da Reforma Psiquiátrica fezsua aposta. De acordo como autor, a ação psicossocial que caracteriza os serviços substitutivos aponta para o limite entre o individual (clínica) e o coletivo (política) presente nessa experiência. A inseparabilidade entre clínica e política no âmbito do cuidado em saúde mental é compatível com a adoção do pressuposto territorial como "unidade geográfica de referência" (Delgado, 1999, p.3). Segundo Delgado (1999, p. 117), “o território não é (apenas) o bairro de domićlio do sujeito, mas o conjunto de referências sócio-culturais e econômicas que desenham a moldura de seu cotidiano, de seu projeto de vida, de sua inserção no mundo". Então, quando se fala do território como unidade de referência, não se está dizendo apenas que os serviços têm responsabilidade sob um determinado território, e sim que devem levar em conta, em suas intervenções, todo um conjunto de signos que constitui o território existencial de seus usuários, que também inclui os vetores políticos que o atravessam, inclusive no sentido da construção de novos territórios possíveis, que não estejam referidos a uma lógica manicomial.

Além disso, com o auxílio teórico de autores como Deleuze e Guattari, entendemos que movimentos de desterritorialização são imprescindíveis à construção de novos territórios, tanto para os serviços de saúde mental, como para os usuários desses serviços. O movimento de desinstitucionalização exige uma desterritorialização no sentido da composição de dispositivos voltados para o exterior do território manicomial. A própria construção da possibilidade de desterritorializar-se é uma alternativa interessante no combate a qualquer processo institucionalizante, uma vez que uma das características próprias às instituições é o seu solipsismo, isto é, o fechamento sobre si mesma e a consequente dificuldade de abertura para a exterioridade. No sentido inverso, abrir-se para outros - múltiplos - territórios é um movimento empreendido no sentido da desinstitucionalização. Construir novos territórios existenciais, tanto para os serviços de saúde mental, como para seus usuários, é, portanto, um movimento que julgamos estar em consonância com as diretrizes das políticas de desinstitucionalização. Nesse 
sentido, o dispositivo do AT nos parece fundamental, já que essa prática se constitui justamente pela construção de alternativas ao isolamento institucional e subjetivo.

Falando do território em Deleuze, Zourabichivili (2004, p. 20) diz:

Inspirado antes na etologia do que na política, o conceito de território decerto implica o espaço, mas não consiste na delimitação objetiva de um lugar geográfico. O valor do território é existencial: ele circunscreve, para cada um, o campo do familiar e do vinculante, marca as distâncias em relação a outrem e protege do caos.

Como se vê, a ideia de território apresentada por Delgado tem pontos de contato com as noções trabalhadas por Deleuze e Guattari (1995). Neste artigo, a nossa aposta é a de que alguns dos conceitos engendrados por Deleuze e Guattari em sua prática filosófica possam funcionar como intercessores ${ }^{4}$ do pensamento que tentamos aqui empreender sobre a prática do AT, já que este, como clínica em movimento (Palombini et al., 2008), também é entendido como um instrumento clínico-político de expansão de territórios existenciais e construção de redes afetivas na cidade.

Segundo Araújo (2006), "o território é a instância que garante um mínimo de constância à vida" (p. 106), não sendo "dado como forma pronta e organizada e sim advindo de uma instância autoconstrutiva" (p. 110). O território seria a passagem do caos a alguma ordem, sendo essa passagem produzida "por uma função autoconstrutiva, autocriativa, autoprodutiva ou maquínica" (Araújo, 2006, p. 110). O caráter auto da produção de territórios evidencia a inseparabilidade entre sujeito e objeto, pois assim entendidos estes são "partes conseqüentes do próprio processo de constituição" (Araújo, 2006, p. 110). O território é, então, uma zona de domínio, é o meio tornado expressivo, já que é autoconstruído. Para Zourabichivili (2004, p. 20), o território é a "marca constituinte de um domínio, de uma permanência, não de um sujeito". Falar de território é, então, falar de um processo constituinte, que envolve movimentos de territorialização, desterritorialização e reterritorialização. Em O Abecedário de Gilles Deleuze (1989), o filósofo afirma que "não há território sem um vetor de saída do território, e não há saída do território, ou seja, desterritorialização, sem, ao mesmo tempo, um esforço para se reterritorializar em outra parte.”.

Para Deleuze e Guattari (2010), a realidade se constitui por um processo incessante de produção que é propulsionado pelo desejo. Assim, novas realidades são produzidas pelo - e no - desejo, incluindo-se aqui a produção de novos territórios existenciais. A renúncia à oposição sujeito-objeto leva os autores a pensarem o desejo como um agenciamento, que é sempre coletivo, seja em seu conteúdo - agenciamento maquínico de corpos - ou em sua dimensão expressiva - agenciamento coletivo de enunciação. Para Zourabichivili (2004, p. 8), estamos diante de um agenciamento quando podemos "identificar e descrever o acoplamento de um conjunto de relações materiais e de um regime de signos correspondente".

Cada um de nós é atravessado tanto por "agenciamentos sociais" - molares - como por "agenciamentos locais" - moleculares (Zourabichivili, 2004, p. 8), sendo cada um de nós também um agenciamento $^{5}$. Os agenciamentos sociais são definidos como "códigos específicos, que se caracterizam por uma forma relativamente estável e por um funcionamento reprodutor: tendem a reduzir o campo de experimentação de seu desejo a uma divisão preestabelecida" (Zourabichivili, 2004, p. 8). Os agenciamentos locais, de outra forma, dizem respeito à "maneira como o indivíduo investe e participa da reprodução" (Zourabichivili, 2004, p. 8) de agenciamentos sociais. Mas, o que importa destacar é que "os mesmos elementos existentes nos fluxos, nos estratos, nos agenciamentos, podem organizarse segundo um modo molar ou segundo um modo molecular" (Guattari \& Rolnik, 2005, pp. 385-386). Há então uma ordem molar, que pode ser representada pelas regras ou pelas leis, e uma ordem molecular, que diz respeito às multiplicidades que se agenciam naquele espaço.

Segundo Guattari e Rolnik (2005, p. 386), "a ordem molar corresponde às estratificações que delimitam objetos, sujeitos, representações e seus sistemas de referência. A ordem molecular, ao contrário, é a dos fluxos, dos devires, das transições de fases, das intensidades". As ordens molar e molecular também podem ser entendidas respectivamente como linhas de segmentaridade rígida ou flexível (Haesbaert, 2004, p.108). A estas duas "linhas", Deleuze acrescenta as "chamadas linhas de fuga ou de desterritorialização efetiva, abstratas, as 'de maior gradiente', que permitem ultrapassar segmentos e limiares, rumo ao desconhecido, ao inesperado e ao ainda não existente" (Deleuze \& Parnet, 1998, citado por Haesbaert, 2004, p. 115).

Para Deleuze e Guattari, o processo de desterritorialização também está ligado ao pensamento. Pensar é, para os filósofos, problematizar. Há no pensar um movimento de criação que não é natural, pois sempre depende de um processo, de um movimentarse. É importante frisar que, na perspectiva dos autores, o pensamento também não se separa do desejo, por 
isso a importância de falarmos sobre a relação do pensamento com a desterritorialização. Há um duplo movimento no desejo, que é por um lado territorial e por outro desterritorializante. Desejar é ao mesmo tempo construir territórios e se desterritorializar. Vejamos, então, alguns relatos de experiências na cidade, em que o AT funcionou como um dispositivo atuante no sentido da construção de novos territórios existenciais para os serviços e para seus usuários, por meio da produção desejante de agenciamentos inéditos.

\section{Cartografias do dia a dia}

O encontro com a diferença presente na loucura - às vezes expressa como indiferença através de um silêncio desconcertante, outras vezes como um infinito transbordar de palavras e gestos estereotipados que não parecem levar a lugar algum - é sempre instabilizador. No entanto, a sensação mais premente no contato com esses diversos ritmos de existência era a de que algumas pessoas pareciam estar presas a formas determinadas de existir, de desejar, de estar no mundo, numa paralisia que podia até se expressar em alta velocidade, mas que não deixava de produzir uma sensação de entorpecimento.

O curioso é que a repetição desse contato produzia em mim um efeito de diferença. Talvez o hiperdimensionamento de certas maneiras de ser fosse o que mais me saltasse aos olhos: ora eu via um engessamento persistente expresso em formas ritualizadas de existência, ora um flutuar incessante que não permitia nenhuma permanência, mesmo que provisória. Um dos usuários do CAPS um dia diz que "viver a vida inteira preso não é uma coisa boa", e acrescenta: "não que eu esteja preso, mas viver a vida inteira sofrendo é como estar numa prisão".

Essa sensação de imobilidade me levou a pensar essa experiência como uma impossibilidade de trânsito, como se não houvesse nenhuma possibilidade de expressão que não estivesse esquadrinhada por uma determinada forma que delimitava previamente o campo de experimentação. Porém, não é essa a sensação de todos nós no mundo contemporâneo? Não é essa produção massificante de subjetividades que caracteriza a forma de operar do capitalismo? A lógica do consumo não tenta forjar uma sensação de eterno presente, que encontra no Carpe Diem o seu caráter pretensamente revolucionário, inspirado também na noção de liberdade como "livre-arbítrio"? Guattari (1992, p. 169) aponta o paradoxo presente em uma sociedade em que tudo circula em alta velocidade, mas tudo parece estar imóvel: enfatizemos imediatamente o paradoxo. Tudo circula: as músicas, os slogans publicitários, os turistas, os chips da informática, as filiais industriais, e, ao mesmo tempo, tudo parece petrificar-se, permanecer no lugar, tanto as diferenças se esbatem entre as coisas, entre os homens e os estados de coisas. No seio de espaços padronizados, tudo se tornou intercambiável, equivalente.

Se existe algo que aproxima a experiência, que, aos meus olhos, parecia ser a da loucura $^{6}$, e o modo de produção de subjetividades da contemporaneidade, essa semelhança está no fechamento para novas possibilidades de existência, na repetição sintomática desse fechamento, na impossibilidade de trânsito entre territórios distintos, através de desterritorializações que levem à criação de territórios inéditos. Por outro lado, a experiência de estranhamento produzida pela "relação diferente com o mundo" (Guattari, 1992, p. 183) presente na loucura, em sua "vertigem caótica" (Guattari, 1992, p. 199), era o que produzia em mim desterritorializações e colocava o meu próprio modo de existência em xeque. Portanto, essa outra forma de estar no mundo, a que se dá o nome de loucura, e que também envolve outra temporalidade, ou outra relação com o tempo (Pelbart, 1993), fala também da nossa maneira de viver, à medida que se apresenta como algo a que nós - os "não loucos" - não temos acesso em nossa "vertigem ordenada" ou "organizada", como se diz no jargão psi.

Como at, o meu papel era o de conseguir participar dos fluxos, de entrar num "devir-louco", de acompanhar a temporalidade de cada um, a fim de auxiliar algumas pessoas na construção de um território possível, na constituição de uma zona mínima de domínio a partir da qual se pode viver, isto é, de um plano de consistência em que o desejo pode se expressar. Deleuze (Deleuze \& Parnet, 1998, p. 106) chega a dizer que o plano de consistência é "idêntico ao desejo". Só se deseja quando se constrói, no mesmo tempo, um plano de consistência no qual se pode desejar. O plano de consistência é também um plano de imanência em que as multiplicidades se agenciam. Se há agenciamento, há plano de consistência, e se há plano de consistência, há um desejo que o traça "no curso de seu processo" (Deleuze \& Parnet, 1998, p. 116), e, ainda, se há agenciamento, "a construção do plano é uma política, ela engaja, necessariamente, um 'coletivo', agenciamentos coletivos, um conjunto de devires sociais" (Deleuze \& Parnet, 1998, p. 107). Estávamos todos tentando expandir nossos territórios de vida, nossos agenciamentos, e o que fazíamos era, em cada experiência, sem dúvida uma prática de resistência a toda "identidade prêt-à-porter" 
(Rolnik, 1997, p. 5). Mas, de que maneira isso ocorre no dia a dia de trabalho do at? Por meio de relatos de experiências no território, pretendo apresentar alguns dos conceitos trabalhados acima, relacionando-os ao dia a dia do trabalho do at.

\section{Bloco carnavalesco "Loucura Suburbana"}

O encontro com o bloco carnavalesco "Loucura Suburbana" foi um bom encontro. Para Spinoza (1973), filósofo do século XVII, um bom encontro se dá quando a potência para agir e para pensar que um determinado corpo possui passa de um estado menos potente para um estado mais potente. De forma contrária, um mau encontro se produz quando essa mesma potência passa de um estado mais potente para um estado menos potente. Um bom encontro é, assim, uma composição em que dois ou mais corpos fortalecem a sua potência e complexificam as formas pelas quais afetam e são afetados. No encontro que tive com o bloco, composições puderam ser experimentadas na medida em que novos territórios foram construídos no sentido de um aumento de potência, tanto do território da cidade como dos territórios dos serviços de saúde mental e de seus usuários, uma vez que estes puderam complexificar as formas pelas quais se relacionavam uns com os outros.

O bloco foi fundado em 2001 e desfilou pela nona vez no Carnaval de 2009. Usuários de serviços de saúde mental da área, técnicos e músicos da região participam de todo o processo de criação do bloco, desde a composição de sambas à escolha das fantasias que serão usadas no desfile. Uma das imagens marcantes dessa manifestação cultural de resistência é a saída do bloco para as ruas. O IMAS Nise da Silveira abre as suas portas e o bloco toma as ruas do bairro sem nenhuma cerimônia. Os encontros que o bloco promove nessa abertura para a cidade fazem parte de um duplo movimento: de um lado, há o encontro dos usuários com a diferença, o inesperado, presente nas ruas, e de outro, o encontro do bairro com o bloco. Esses encontros têm efeitos diversos, tanto para os integrantes do bloco, como para a cidade por onde o bloco passa.

O bloco carnavalesco "Loucura Suburbana" também é uma manifestação de resistência cultural que acompanha um movimento de renascimento do carnaval de rua, visto em toda a cidade do Rio de Janeiro nos últimos anos. É também a organização de um grupo de pessoas em torno da alegria ${ }^{7}$. É, assim, uma construção coletiva; a sua saída nas quintas-feiras que antecedem o carnaval só acontece por meio de uma série de agenciamentos. Além do desfile do bloco, que acontece anualmente, também tive a oportunidade de participar, juntamente com o bloco carnavalesco, da produção e da realização do show de abertura do II Fórum Internacional de Saúde Coletiva, Saúde Mental $e$ Direitos Humanos, realizado na Universidade Estadual do Rio de Janeiro (UERJ).

O convite para a abertura do II Fórum partiu da comissão organizadora do evento, mas coube a nós a produção artística do show. Os preparativos incluíram uma série de reuniões para a criação do formato do show e para a escolha dos sambas que seriam tocados, um trabalho de figurino, um ensaio, o contato com a bateria da Escola de Samba Caprichosos de Pilares, e toda a "operação" de transporte de material e de gente no dia da apresentação. Todo esse trabalho, que também existe na preparação para o desfile anual do bloco, funciona como um plano de consistência para aqueles que participam. A saída para as ruas só acontece em virtude da criação desse corpo chamado bloco; é ele que dá um sentido compartilhado à saída, na medida em que é um agenciamento. Segundo Deleuze e Parnet (1998, p. 112), "qualquer agenciamento expressa e faz um desejo construindo o plano que o torna possível, e, tornando-o possível, o efetua".

No desfile de 2007 (seis anos depois do primeiro desfile) os integrantes do bloco foram surpreendidos pelos moradores da região, que aguardavam o bloco sair na porta do Instituto. A presença da comunidade demonstra que o bloco pôde aproximar o bairro do IMAS - ou vice-versa -, transformando uma relação estigmatizada - de parte a parte - por quase um século de convivência. A (des)estigmação da "loucura" e da "normalidade" - , no entanto, é apenas um dos efeitos que esse encontro produz. O carnaval é uma festa profana, e, como todas as festividades desse gênero, tende a se desenrolar em um ambiente em que as hierarquias sociais estão "suspensas", assim como as identidades em que temos a ilusão de nos reconhecermos como idênticos a nós mesmos; no carnaval, todos são foliões. Mas, que efeitos esse encontro produz para os foliões?

No caso do bloco "Loucura Suburbana", o carnaval representa a suspensão de identidades como as de técnico e de usuário, e de oposições, como a do hospital em relação à cidade. Todos saem às ruas com o objetivo comum de desfilar no mesmo bloco carnavalesco pelas ruas do Engenho de Dentro. Tanto técnicos como usuários confeccionam fantasias e se misturam aos foliões que pulam o carnaval de rua na cidade. $\mathrm{O}$ ato de fantasiar-se gera em todos, sejam técnicos, usuários ou meros foliões, a possibilidade de experimentação de outras identidades. Assim, o inusitado encontro do pirata com a baiana pode 
produzir novas possibilidades de existência para ambos, no sentido de novas conexões possíveis, que não sejam determinadas pelas funções ou papéis que ambos exercem ou ocupam no dia a dia. Mas, o que a cidade ganha nesse encontro?

As ruas se reduziram a espaços de passagem. Desse modo, é interessante que o bloco, que também passa, mas não para chegar a algum lugar, venha ocupar o espaço das ruas de uma forma que parece nova, mas que já fez parte da vida da maioria das pessoas que moravam no subúrbio do Rio de Janeiro: a cadeira na calçada, o convívio nas praças, as rodas de samba, o carnaval de rua, etc. O bloco promove uma reocupação do espaço público, que passa a ser um lugar onde é possível haver trocas, uma certa contaminação com o diferente, que pode ser muito interessante como resistência à onda individualizante, que faz o comum não ter mais sentido.

Mas, como fazer para levar esses efeitos para a vida corriqueira, o dia a dia sem carnaval? Com o instrumental teórico desse trabalho, podese dizer que a saída do bloco para as ruas provoca desterritorializações que sempre vêm acompanhadas de reterritorializações. Ou seja, é saudável não permanecermos desterritorializados, como aqueles que parecem flutuar no tempo sem conseguir firmar os pés no chão. O que Deleuze e Guattari propõem não é isso, mas que sejam abertos espaços para que processos de desterritorialização ocorram; é a passagem de um território a outro que abre novas possibilidades de vida, não uma desterritorialização estática. Sendo assim, é possível dizer que as desterritorializações provocadas pela festa são levadas para o dia a dia na medida em que criam novos territórios de existência para os envolvidos. Estes podem ou não permanecer no cotidiano pós-carnaval, mas acreditamos que a simples passagens por essas novas paisagens provoque movimentações em territórios que muitas vezes encontram-se imobilizados.

\section{Jornal "O Bonde Andando"}

$\mathrm{O}$ projeto de expansão das atividades da TV Pinel nos CAPS, que resultou no Jornal "O Bonde Andando" envolveu um grupo de usuários que participou de maneira efetiva na elaboração do jornal, tanto na produção das matérias, como no trabalho de construção de rede no território. O projeto da TV Pinel propunha a criação de estratégias que fortalecessem as experiências artística-cultural-comunicacionais desenvolvidas nos CAPS como forças de articulação entre esses serviços e a comunidade local ${ }^{8}$.
A primeira fase do projeto envolveu a escolha da linguagem a ser usada pelo CAPS na parceria que desenvolveria com a TV Pinel. Diversas possibilidades foram traçadas, como uma biblioteca, um vídeo e outras modalidades de intervenções culturais. No entanto, nas reuniões preliminares, grande parte dos usuários apontava um descontentamento relativo aos vínculos sociais construídos naquele território. Muitas falas indicavam para alguma impossibilidade de trânsito atribuída a estigmatização promovida pela comunidade em relação aos usuários do CAPS. A partir disso, a ideia de um jornal de bairro nos pareceu adequada, uma vez que o próprio processo de produção do jornal exigiria um trabalho nesse território no sentido da criação de novas possibilidades de vínculos que se construíssem por vias diversas a oposição moradores/usuários do CAPS. Além disso, o jornal seria um produto interessante não só para os usuários - que também residem naquela área -, como para a comunidade como um todo. Nesse processo, mais uma vez apostávamos na extrapolação dos limites do CAPS no sentido do território urbano ao qual o próprio serviço pertence.

Quando o grupo se define pelo jornal outra fase se inicia, em que são realizadas dinâmicas e oficinas expressivas, voltadas para a criação do jornal e para a preparação das incursões no território. $\mathrm{O}$ modelo era o de um jornal de bairro, que conteria matérias relacionadas ao cotidiano da comunidade, como dicas de um salão de beleza, receitas de um restaurante local, dicas de eventos culturais e centros de cultura, como o SESC, entre outros. Foram formados grupos que seriam responsáveis por cada coluna, cabendo aos seus integrantes buscar as suas matérias no território de adjacência do CAPS. Os grupos eram formados por um técnico ou por um estagiário e alguns usuários, e a proposta era que, em nossas reportagens, nós nos apresentássemos como a equipe do "Jornal O Bonde Andando". No processo de elaboração do jornal, todos nos tornamos "aprendizes de jornalistas".

Cada grupo responsável pelas colunas do jornal teve missões diferentes, o que tornou muito rico todo o processo. O grupo responsável pela coluna de esportes saiu pelo bairro à procura de espaços em que são realizados eventos esportivos; o grupo responsável pela coluna de dicas de beleza foi a um salão de beleza da área, buscando informações úteis para o tratamento dos cabelos; outro grupo pesquisou sobre a vida de personalidades relacionadas ao subúrbio do Rio de Janeiro, como Nei Lopes; outro entrou em contato com uma escola para promover um concurso de desenho, que premiaria o ganhador com a publicação de seu desenho no jornal; e outro grupo ficou responsável por 
visitar restaurantes à procura de receitas, que sairiam no jornal juntamente com o endereço do estabelecimento. O grupo do qual eu participava ficou responsável pela coluna de poesia. A ideia era que buscássemos um poeta que morasse na região ou que promovesse alguma manifestação cultural na área. Nosso grupo escolheu como primeiro lugar a ser visitado o SESC do Engenho de Dentro. Fomos até lá e conseguimos o contato de uma poetisa, que, além de morar na região, tinha a própria região como tema de alguns de seus poemas. Além disso, passada a fase de criação do jornal, dividimo-nos novamente e saímos pelo bairro para angariar patrocinadores ou anunciantes dispostos a "pegar o nosso bonde".

Todo esse processo, desde a escolha da linguagem que seria utilizada, até a criação do jornal e do seu nome ("Jornal O Bonde Andando"), produziu efeitos de todo o tipo nos participantes. O fato de o grupo não ser estritamente terapêutico, no sentido de ter como fim o tratamento dos usuários, permitiu que novas possibilidades fossem vislumbradas em nossas relações com os espaços, tanto da cidade, como do CAPS, na medida em que este também pôde se tornar um local de articulação da comunidade e de encontro de múltiplas vozes: o CAPS polifônico. Todo o processo se desenvolveu em direção à apropriação de territórios: criar territórios possíveis fora do CAPS e, ao mesmo tempo, fazer do CAPS um local de convergência de múltiplos territórios; novos agenciamentos, tanto no plano molar, como no molecular.

Foi assim que um dos usuários do CAPS, numa Assembleia Geral, propôs que fizéssemos uma feijoada para angariar fundos para o nosso projeto, já que não obtivemos muito sucesso com as doações e os anúncios publicitários - os 300 exemplares da nossa tiragem não atraíram as expectativas de marketing dos comerciantes. A feijoada de pré-lançamento do jornal aconteceu e foi um sucesso. As pessoas levaram familiares e amigos, os músicos nos presentearam com a roda de samba, todos se divertiram, e até uma autoridade pública da região compareceu. Com esse evento, conseguimos levar um pouco da cidade para o CAPS, fazendo com que novos ares circulassem naquele território.

\section{Considerações finais}

A título de conclusão, volto ao século XVII para lembrar um filósofo que entendia os bons e os maus encontros, respectivamente, como aumento e diminuição da potência de agir dos nossos corpos. Como foi dito anteriormente, Spinoza (1973) dizia que um bom encontro comporta uma composição, enquanto que um mau encontro, uma decomposição de nossa potência de ser e de agir. Essa dimensão do encontro enunciada por Spinoza e incorporada também por Deleuze, dá-se no mínimo entre dois corpos, produzindo afetos de tristeza ou de alegria. Nessa dinâmica, cada corpo possui uma potência de afetar e de ser afetado, que pode se expandir ou se retrair, dependendo dos encontros que realiza. Um encontro contém sempre uma desterritorialização; dois ou mais corpos se encontram e, nesse encontro, desterritorializam-se, podendo reterritorializar-se com maior ou menor potência de agir. São os encontros, também, o material do at, que trabalha para construir um plano de imanência em que os mesmos possam se realizar sem hierarquias preestabelecidas.

O território pode ser o território geográfico e ao mesmo tempo o território existencial e, na prática da saúde mental, ser a área de abrangência de um CAPS e ao mesmo tempo um conjunto de signos que faz parte das relações das pessoas com essa região. Assim, é possível pensar o CAPS como fazendo parte da construção do território, construção que se refere aos afetos presentes na relação das pessoas com o próprio território. Ao invés de o CAPS ser entendido como organizador da rede, a própria noção de território pode ser colocada nesse lugar. Nesse sentido, Rotelli (1992) também deve ser lembrado quando fala que as instituições públicas só se transformam ao encontrarem recursos fora de seus limites: desterritorialização, linha de fuga, aumento de potência, construção de um plano de imanência no qual os agenciamentos e os encontros se multipliquem num espaço sem limitações. Para que isso aconteça, é necessário um trabalho permanente de construção da rede no território, que pode ser realizado pelo AT.

A rede de saúde mental deve, então, expandirse para além de seus limites, isto é, transformarse em uma rede que já não é mais da saúde mental nem da saúde como um todo, mas uma rede urbana em que estão contidos múltiplos discursos, múltiplos territórios, múltiplos encontros, múltiplas ideias e múltiplos agenciamentos. E o que procuramos mostrar é que a construção dessa rede, por não dizer mais respeito apenas aos dispositivos de saúde mental, também pode ser a construção de formas inéditas de convivência na cidade, como o que dissemos sobre a reocupação do espaço público produzida pelo desfile de um bloco carnavalesco.

Só que esse trabalho não é simples. A construção de uma rede é um trabalho difícil porque supõe que diversos elementos possam se conectar. Dessa forma, ações pontuais de interlocução com o território urbano não se configuram necessariamente como 
uma construção de rede, pois nada garante que os elementos da rede venham a se interligar. $\mathrm{O}$ trabalho de construção de rede é o trabalho que atua no sentido de fazer a rede funcionar, ou seja, que cria estratégias para que diversos dispositivos da cidade possam estar em conexão permanente. Dessa maneira, o trabalho de construção de rede, que também é o trabalho do at, é um trabalho de promoção de encontros. Tenta-se fazer com que elementos diversos se conectem em um só plano, produzindo novas bifurcações que venham a integrar a rede. Esse trabalho é, portanto, um trabalho de cartografia, que deve estar sempre atento aos "movimentos de transformação da paisagem" (Rolnik, 1989, p. 15) para acompanhar e auxiliar na construção de trajetos inéditos que possam vir a formar novos territórios mais potentes.

\section{Notas}

1 A partir daqui utilizarei a abreviação AT para designar o acompanhamento terapêutico e at para designar o acompanhante terapêutico, assim como Kléber Duarte Barreto (2005), no livro A ética e a técnica do acompanhamento terapêtico: andanças com Dom Quixote e Sancho Pança; e Analice Palombini et al. (2008), no livro Acompanhamento terapêutico na rede pública: a clínica em movimento.

2 Diz-se, hoje em dia, que o modelo de tratamento por internações é um modelo iatrogênico, isto é, os efeitos de internações prolongadas ou recorrentes depõem contra o próprio tratamento da doença mental. Viver em uma instituição é ter uma vida balizada pelas regras institucionais: o louco não tem cidadania - nem autonomia - visto que precisa da tutela da instituição para viver. O manicômio, por ser um espaço em que as trocas sociais são quase nulas, reproduz a exclusão e a estigmatização vivida pelo louco em nossa sociedade. Viver em sociedade é, de outra forma, participar do funcionamento da pólis, adquirir cidadania, ter direitos e deveres, ter a possibilidade de fazer escolhas, construir relações, enfim, sair da posição de tutelado, podendo, assim, participar da criação do seu próprio espaço de vida. Nas palavras de Torquato Neto (1982, p. 359), que escreve em um período de internação no Centro Psiquiátrico Pedro II, atual IMAS Nise da Silveira: "a prisão é um refúgio: é perigoso acostumar-se a ela".

3 Cf. Portaria 336/GM, de 19 de fevereiro de 2002.

4 De acordo com Jorge Vasconcellos (2005, p. 1223), que fala sobre os intercessores na obra de Deleuze, "os intercessores são quaisquer encontros que fazem com que o pensamento saia de sua imobilidade natural, de seu estupor. Sem os intercessores não há criação. Sem eles não há pensamento".

5 Nosso corpo pode ser entendido, tanto como um agenciamento de diferentes partes, quanto como sendo atravessado por múltiplos vetores que se agenciam nele e com ele.

6 Cabe dizer que esta experiência a que me refiro como sendo a da loucura não é tomada como algo que integre a essência do louco, e sim como a experiência que historicamente se constituiu como sendo a da loucura. Mesmo porque não se pode falar em uma experiência "pura" da loucura, pois o "louco" de hoje já é produto da maneira pela qual a loucura foi entendida ao longo de sua história de oposição à razão.

7 Devo essa ideia a Luiza Helena Nunes Ermel, trabalhadora incansável em combater qualquer forma de opressão, transformando-a em alegria, em planos de consistência para o desejo se expressar, sempre coletivamente.

8 Toja, N. (2008). Despinelizando a TV Pinel para capsular? - Relatório Expansão TV Pinel CAPS. Fase 1: agosto de 2007 a julho de 2008 (p.2).

\section{Referências}

Araújo, F. (2006). Acompanhamento terapêutico e território. In Um passeio esquizo pelo acompanhamento terapêutico: dos especialismos à política da amizade (pp. 99-127). Niterói, RJ: [s.n.].

Barreto, K. D. (2005). A ética e a técnica do acompanhamento terapêutico: andanças com Dom Quixote e Sancho Pança. São Paulo: Unimarco.

Constituição da República Federativa do Brasil de 1988. (2009). São Paulo: Saraiva.

Declaração de Caracas. (1990). Adotada pela Organização Mundial de Saúde em Caracas, Venezuela, em 14 de novembro de 1990. Acesso em 11 de fevereiro, 2014, em http://bvsms.saude.gov.br/bvs/publicacoes/declaracao caracas.pdf

Deleuze, G. (1989). O Abecedário de Gilles Deleuze [versão eletrônica]. Acesso em 29 de setembro, 2008, em http:// www.dossie deleuze.blogger.com.br/index.html

Deleuze, G. \& Guattari, F. (1995). Mil platôs: capitalismo e esquizofrenia, Vol. 1 (A. Guerra Neto \& C. P. Costa, Trads.). Rio de Janeiro: Ed. 34.

Deleuze, G. \& Guattari, F. (2010). O Anti-Édipo: capitalismo e esquizofrenia (L. B. L. Orlandi, Trad.). São Paulo: Ed. 34.

Deleuze, G. \& Parnet, C. (1998). Diálogos (E. A. Ribeiro, Trad.). São Paulo: Escuta. (Obra original publicada em 1977)

Delgado, P. G. (1999). Atendimento psicossocial na metrópole: algumas questões iniciais. Cadernos IPUB, 14, 113-121.

Guattari, F. (1992). Caosmose: um novo paradigma estético. São Paulo: Ed 34.

Guattari, F. \& Rolnik, S. (2005). Micropolítica: cartografias do desejo. Petrópolis, RJ: Vozes.

Haesbaert, R. (2004). O mito da desterritorialização: do "fim dos territórios" à multiterritorialidade. Rio de Janeiro: Bertrand Brasil.

Ministério da Saúde. (1986). VII Conferência Nacional de saúde. Relatório final. Brasília: Autor.

Ministério da Saúde. (2005). Reforma Psiquiátrica e política de Saúde mental no Brasil; Conferência Regional de Reforma dos Serviços de Saúde mental: 15 anos depois de Caracas. Acesso em 29 de setembro, 2008, em http://portal.saude.gov. br/portal/arquivos/pdf/Relatorio15\%20anos\%20Caracas.pdf

Neto, T. (1982). Os últimos dias de Paupéria (do lado de dentro). São Paulo: Ed. Max Limonad.

Palombini, A. L. et al. (2008). Acompanhamento terapêutico na rede pública: a clínica em movimento. Porto Alegre: Editora UFRGS.

Passos, E. (2004). O CAPS como Matriz das Ações Psicossociais no Território. ACADEMUS, 3(4). Acesso em 29 de setembro, 2008, em http://www.saude.rio.rj.gov.br/saude/pubsms/ media/cuidado_nos_caps.pdf 
Pelbart, P. P. (1993). A nau do tempo-rei: sete ensaios sobre o tempo da loucura. Rio de Janeiro: Imago Ed.

Rolnik, S. (1989). Cartografia sentimental, transformações contemporâneas do desejo. São Paulo: Editora Estação Liberdade.

Rolnik, S. (1997). Clínica Nômade. In Equipe de Acompanhantes Terapêuticos do Hospital-Dia A Casa (Org.), Crise e cidade: acompanhamento terapêutico (pp. 83-87). São Paulo: Educ.

Rotelli, F. (1992). O trabalho de saúde mental no território. In E. Kalil (Org.), Saúde mental e cidadania no contexto dos sistemas locais de saúde (pp. 75-80). São Paulo-Salvador: Editora Hucitec.

Vasconcellos, J. (2005). A filosofia e seus intercessores: Deleuze e a não-filosofia. Educação \& Sociedade, 26(93), 1217-1227.

Spinoza, B. (1973). Ética (Coleção Os Pensadores). São Paulo: Abril Cultural.

Zourabichvili, F. (2004). O vocabulário de Deleuze [versão eletrônica]. Acesso em 3 de agosto, 2009, em http://www. freewebtown.com/polis contemp/FZ vocabulario G

Recebido em: 12/10/2009

Revisão em: 20/04/2012

Aceite em: 03/09/2013

Mariana Ribeiro Marques é Mestre em Psicologia Clínica pela Pontifícia Universidade Católica do Rio de Janeiro/RJ, Brasil; realizou estágio no CAPS Clarice Lispector através do Programa de Estágio Acadêmico Bolsista, financiado pela Prefeitura da cidade do Rio de Janeiro; Atualmente atua nas áreas de Psicologia Social, Inclusão Social e Saúde Pública. Endereço: Rua Benjamin Constant, 144, casa 1 Glória, Rio de Janeiro/RJ, Brasil. CEP: 20241-150. E-mail: marirmarques@gmail.com

\section{Como citar:}

Marques, M. R. (2013). A prática do Acompanhamento terapêutico como estratégia de expansão territorial: uma incursão cartográfica. Psicologia \& Sociedade, 25(n. spe. 2), 31-40. 